\title{
HERENCIA DEMONÍACA EN LOS PERSONAJES DE BAJO LA LLUVIA DIOS NO EXISTE DE WARREN ULLOA
}

\author{
DIABOLIC LEGACY IN BAJO LA LLUVIA DIOS NO EXISTE FROM WARREN ULLOA**
}

\section{Selene Fallas Salazar*}

\begin{abstract}
RESUMEN
En este artículo se establece una relación entre los personajes de la novela Bajo la lluvia Dios no existe con las características que la tradición judeocristiana ha otorgado al demonio. Se realiza un análisis de los personajes de la novela y se observa la relación que, desde el discurso cristiano, podrían acercarlos a lo demoníaco. Se analiza que en la novela la escritura se relaciona con el final. La muerte es quien cierra el círculo.

Palabras clave: literatura costarricense, Ulloa Warren, Bajo la lluvia Dios no existe, herencia demoníaca.
\end{abstract}

\begin{abstract}
This paper establishes a relationship between the characters in the novel Bajo la lluvia Dios no existe ("Under the rain God doesn't exist") with the features that the Judeo-Christian tradition has given to the devil. An analysis of the characters of the novel to see the relationship, from the Christian discourse, could bring them closer to the demonic. We analyze that in the novel the writing process relates to the end. Death is who closes the circle.

Key Words: Costa Rican Literature, Ulloa Warren, Bajo la lluvia Dios no existe, evil heritage.
\end{abstract}




\section{Relación entre el Diablo y el mal}

En muchas culturas existen deidades malignas que alteran la cotidianidad de los actores sociales. Los relatos etnográficos y mitológicos dan cuenta de que, por ejemplo, en la cultura escandinava se hablaba del inquietante Loki, en la griega de Hades, en la mesopotámica de Marduk, en fin, muchas culturas han tenido y tienen sus figuras demoníacas, las cuales ayudan a equilibrar la balanza entre lo bueno y lo perverso.

En el entorno costarricense, la palabra "demonio" apunta hacia los símbolos malignos que figuran en la Biblia; es decir, que en esta cultura cuando se habla del mal, suele pensarse en Satanás, Lucifer o Belcebú. La novela Bajo la lluvia Dios no existe posee varios elementos y personajes que se pueden relacionar con esta tradición de lo demoníaco, al menos, con lo que la herencia judeocristiana ha catalogado de ese modo.

García Font y García Jorba (1996:11) señalan que el poder maléfico queda diversificado según las funciones que encarna, de esta manera los demonios son entidades con funciones determinadas y con base en estas, se establece la jerarquía de cada uno. Estos mitos adquieren presencia en la mentalidad colectiva y, se presentan, a veces, de manera insospechada en el quehacer intelectual, artístico o cultural. Eliade (1991:8) por su parte, llega a afirmar que el ser humano es lo que es hoy (un ser mortal, sexuado y cultural) a consecuencia de las intervenciones de los seres sobrenaturales dioses o demonios.

Los ejemplos literarios permiten observar que una de las representaciones más comunes del mal ha sido la de concebirlo encarnado en algún ser: Mefistófeles en Fausto de Goethe, Godofredo en Paradiso de Lezama Lima, el profesor Vóland en El Maestro y Margarita de Mijaíl Bulgákov, el apuesto y rico caballero en el cuento de Carmen Lyra "La suegra del diablo" son personajes que intervienen en la cotidianeidad de los actores sociales y representan lo que socialmente, se ha señalado como incorrecto.
El diablo, en este caso, se entenderá como una construcción social, como un referente literario y se analizarán las características que se han establecido para él y, esas cualidades, se relacionarán con los personajes de la novela, en busca de oposiciones y similitudes.

\section{Los personajes de Bajo la lluvia Dios no existe y sus relaciones con lo demoníaco}

A continuación se anotarán algunas relaciones de los personajes de la novela de Ulloa y sus aproximaciones con aquello que el cristianismo ha caracterizado como demoníaco:

\section{María Belén}

Mabe es una adolescente que, por su sola condición femenina se relaciona con la sensualidad demoníaca, en Occidente, tradicionalmente, encarnada por personajes como Lilith o Eva. Los demonios asociados a Lilith, de acuerdo con Massimo Centini (2004:25) se caracterizan por alterar el orden fisiológico del amor, «que es fundamento de la vida familiar y comunitaria, y por esta razón concreta Lilith es una virgen sin leche, una mujer que se une sin poder llegar a ser madre nunca, y que después de haber encendido en el hombre la lujuria, no lo satisface».

Esto recuerdo el episodio en la novela en que Bernal desea que Mabe le practique una felación y le muestra su miembro, en espera de que ella lo satisfaga, sin embargo, ella responde de esta manera: «ella soltó una carcajada cuando la vio, y me dijo que me la guardara, que tranquilizara mis hormonas, porque la única persona que podría elegir cuándo hacerlo y cuándo no era ella ¿Le quedó claro, maecillo?, especificó con sarcasmo» (Ulloa, 2011:32).

Por otro lado, Eva es la mujer ingenua que, tentada por la serpiente, desobedece a Dios y come del fruto prohibido, el cual comparte con su marido, esto provoca que la humanidad sea condenada y expulsada del Paraíso ¿Cómo es que estas dos mujeres se relacionan con la adolescente María Belén?, cuyo nombre, además, 
solo recuerda el origen del cristianismo, pues fue María quien dio a luz a Jesús y este nacimiento, de acuerdo con el relato bíblico se produjo, precisamente, en la ciudad de Belén. Después de más de dos mil años del relato cristiano, la joven María que se describe, no tiene relación con las tradicionales virtudes femeninas exaltadas en la Biblia, pues al contrario de la también adolescente María, Mabe ya no es virgen, de hecho, se describe como una joven dueña de su sexualidad y, en opinión de Bernal, bastante experimentada: «Su carita de niña contrastaba con el expediente que tenía entre las piernas» (Ulloa, 2011:13).

Mabe no recibe la fecundación de su vientre de manera sumisa, ni como un mandato divino. Ella se rehúsa a dar vida, al saber que está embarazada, ella decide abortar: «aproveché entonces abortar cuando estuve completamente segura, mandé a traer unas pastillas clandestinas a Panamá» (Ulloa, 2011:187) de esta manera, el personaje de Mabe se diferencia de Eva y de María, pero se acerca a Lilith.

Aunque hay muchas variantes entre Mabe y Eva, también hay algunas similitudes: por ejemplo, Eva es quien da el fruto prohibido a Adán, lo inicia en el pecado y lo condena con ella, Mabe inicia a Bernal en el mundo del sexo y de las drogas (de los hongos para ser más específicos). Además, si se elimina la $\mathrm{m}$ del hipocorístico con que se identifica a este personaje, fonéticamente se logra un abe/ nombre de Eva invertido. Todo texto es el génesis de un mundo que se muestra al narrador, esta génesis tiene como pilares a dos jóvenes, a un nuevo Adán y una nueva Eva, que también tomarán decisiones diferentes a sus antecesores y darán a su historia un final que varía mucho del antiguo relato hebreo.

El título de la novela Bajo la lluvia Dios no existe es el que da nombre al poemario escrito por Mabe, ella explica: «En ese momento sentí que bajo la lluvia dios es parte de nosotros y nosotros parte del mae, y Dios, así con mayúscula, no existe como tal, porque Dios o esa fuerza creadora nos necesita para ser dios, de lo contrario no podría serlo» (Ulloa, 2011:52). Mabe, bajo la lluvia, logró entender que el ser humano puede no tener creador, que en el ser humano está la capacidad de librarse de ese ente superior o divino que controla los destinos, de esta manera, ella decide poner fin a este juego de poder, pues no quiere procrear, sabe que su hijo heredará el mismo infierno que ella: «el chamaquito, nuestro hijo, no me iba a detener y a él tampoco quería heredarle un mundo de mierda como este» (Ulloa, 2011:187).

Eva, en cambio, en el relato tradicional, no se atreve a dudar de Dios y, simplemente, acepta sumisa el castigo que Él le impone a ella y a su descendencia. Eva procrea una estirpe condenada, "maldita", aún así no tiene poder sobre su cuerpo para rechazar este mandato, de algún modo, en la antigua leyenda judeocristiano se observa una mujer incapaz de asumir el control, sin ningún poder; en este nuevo relato se observa una joven que está creando un mundo (un poemario) una mujer que tiene la función de dios, valga la pena recordar que, en el relato del Génesis, el mundo se crea con la palabra, Mabe es, en este nuevo universo narrado, quien tiene la facultad de crear, de hacer un mundo con su palabra (su poesía).

Mabe se asemeja a Lilith en tanto mujer desobediente de dios, además Lilith se relacionaba con la muerte de los fetos, en la novela, Mabe aborta a su hijo (cabe señalar, además, que el nickname que usa Mabe para chatear es Lilith). En la tradición sumeria, explica Centini (2004: 25) Lilith se relaciona con el libertinaje, es un demonio que excita a la voluptuosidad.

Este es el rol que cumple Mabe en la vida de Bernal. El pecado de Lilith fue no someterse al hombre, del mismo modo que el pecado de Mabe fue no someterse a su padre, rechazar el incesto, obviamente, el que su padre intentara abusar de ella, provoca que María Belén le pierda el respeto a Agustín, sin embargo, ella no intenta huir de su padre, tal vez, como doña Ofelia, no está dispuesta a renunciar a la vida que lleva, de este modo Agustín sigue teniendo poder sobre ambas, por mucho que Mabe le grite a su padre, no se ha liberado de él: «Ella se quitó la mano de su tata y lo escupió; Agustín levantó la mano, pero se detuvo al darse cuenta de que 
yo lo estaba viendo; parecía que me iba a decir algo hasta que Mabe empezó a gritar. ¡Diay pégueme, vamos, para que vea Bernal la clase de comemierda que sos!» (Ulloa, 2011:102).

Mabe sabe que su cuerpo despierta el deseo de Bernal, pero, en principio, ella lo que quiere es involucrarlo en la venta de hongos, pues es un joven popular en el Colegio, para lograr que acepte el negocio Mabe se le acerca de la manera en que su socio le sugiere. Sin embargo, su personaje, después se libera, incluso de su vínculo con Ratatás: «¿Entonces no hará nada por ese mae?, pregunté. Un contundente "ni picha" salió de su boca. Si llama a esa hora de seguro le contestará Agustín. Que se arregle con él directamente. No sé porqué tanto mosquero por hablar conmigo. La verdad que Ratatás está clausurado de mi vida, punto» (Ulloa, 2011:167).

De este modo Mabe se convierte en la antítesis de las mujeres que en la Biblia se muestran como ejemplo, aquellas dispuestas a obedecer al patriarca en todo (incluso si eso implica el incesto) aquellas que se mantienen vírgenes y salvas del pecado original y aquellas que ven en la maternidad una bendición.

\section{Ratatás}

Este personaje cuyo sobrenombre es un anagrama de Satanás, pues es cuestión de cambiar la "r" por una "s" y la segunda " $\mathrm{t}$ " por una " $n$ ", tiene algunas similitudes con lo demoníaco, principalmente con el disfraz y la mentira. Centini (2004:25) explica que la idea del pecado sexual como origen del mal proviene de un texto apócrifo del Antiguo Testamento donde se narra que las mujeres de la tierra sedujeron a algunos ángeles del cielo y los hijos de esta unión aprendieron varios oficios, entre ellos, la recolección de plantas y raíces.

Ratatás se caracteriza como un personaje que sabe de plantas, del cuido y siembra, de la recolección, de la selección y preparación de las drogas para el consumo. Es quien inicia a Mabe en este mundo de las opiáceas y el psilosybe, es decir, realiza uno de los oficios que nace con la caída de los ángeles. Además, busca jóvenes ingenuas de barrios pobres y las presenta con el padre de Mabe, quien las explota sexualmente, por último, intentará traficar cocaína, para obtener un buen dinero, sin embargo, su plan se ve frustrado.

Mientras están en la fiesta en que planean distribuir la droga, Ratatás les recuerda a Bernal y Mabe que deben indicar a los clientes que lo mejor es cubrir el hongo con leche condesada para quitarle el sabor amargo. «Dada la advertencia, desapareció como el humo» (Ulloa, 2011:55). La habilidad para desaparecer bajo una nube de humo, suele relacionarse con los magos, otro oficio que se origina de la unión entre los ángeles caídos y las mujeres. Ratatás representa en esta novela a un sirviente del mal, alguien que ayuda para distribuir y potenciar aquellos valores ajenos a la moral cristiana, además colabora con el personaje que representa la encarnación del mal en la novela, Agustín.

Este personaje, además se presenta con varias máscaras, algo que lo relaciona con el mal, del demonio se dice que engaña a la gente, que se presenta con otro rostro. Respecto a Ratatás afirma Bernal «Comprendí entonces la cantidad de máscaras que usaba: metalero, barra brava, estudiante de química de la UCR. Eran solo eso, máscaras, y hasta ahora vi la verdadera cara, con sus dientes oscuros, grandes y deformes» (Ulloa, 2011:169).

Ratatás se ve tentado por el dinero, se relaciona con personajes que representan el verdadero mal y termina siendo sacrificado, su caracterización es la de un demonio menor que es utilizado para atormentar a los "hombres", sin embargo, él no tiene ningún estatus jerárquico. Por otro lado, como lo afirma Papini muchas veces en la literatura se presenta al diablo como «al burlador fraudulento, sin embargo, este maestro del engaño fue trufado más de una vez» (Papini, 1968: 91) así ocurre con Ratatás, quien al final termina pobre, sin libertad y solo.

Este personaje y Eugenia son los únicos en la novela, que tiene un linaje humilde, representan a una clase social que está por debajo de los otros personajes, no sorprende, entonces que sus roles dentro de la obra sean de servicio y sacrificio, además, cabe señalar que 
son los únicos personajes que no nacieron en el Valle Central.

Ratatás aparece en la vida de Mabe y de su hermana Mariela, gracias a Agustín, él es una marioneta en manos de un personaje con mayor poder y jerarquía con respecto al mal. Gracias al poder que le brinda el dinero, Agustín puede jugar con el destino de los personajes, incluso e de sus hijas.

\section{Eugenia}

Aunque este personaje es quien cumple la función de amiga o consejera de Bernal y en muchos aspectos es el que más se acerca a la visión judeocristiana del bien, podría relacionarse con lo demoníaco en al menos uno de sus rasgos, su inclinación esotérica: «Tenía inclinación por lo esotérico, le gustaba el tarot y leía el periódico principalmente por el horóscopo. Una vez me leyó el tarot, porque quise saber qué era la vara, pero lo que revelaron las cartas Eugenia nunca me lo quiso traducir; se limitó a decirme, entre evasivas, que las figuras que vio fueron de amor y de locura» (Ulloa, 2011:28).

De acuerdo con lo que expresa el narrador, Eugenia logra ver el futuro de Mabe y Bernal, mucho antes de que la relación se estableciera, en el Diccionario Esotérico de Zaniah se dice que la adivinación se ha asociado con el demonio, pues se creía que los brujos o brujas podían adivinar o conseguir sus propósitos gracias a un pacto con el diablo (Zaniah, 1994:79).

El nombre Eugenia significa de buen origen o de noble nacimiento. En este caso el origen de Eugenia no solo tiene que ver con la humildad y el trabajo (valores muy prestigiosos en la moral cristiana) sino también con el paganismo. La descripción que hace Bernal es la siguiente: "Debajo de la mesita del buró del tata de Eugenia alcancé a ver frascos con líquidos y fotos de gente flotando en su interior. Eran santeros o algo por el estilo, de ahí la influencia de Eugenia y todo aquel revoltijo de creencias y lecturas que provocaron en ella cierto grado de confusión y que tarde o temprano le iban a tostar la jupa, lo cual era natural, puesto que sus papás (que estaban igual o más camotes que ella) le heredaron tanta superstición" (Ulloa, 2011:144).

Eugenia se describe como una mujer convencional, fue seducida a temprana edad, quedó embarazada y como Eva o María, aceptó la maternidad con sumisión, es trabajadora y cariñosa, parece ser la única amiga sincera de Bernal, de hecho, en el entierro de Mabe es la única ante quien Bernal se atreve a llorar: «De pronto sentí en mi hombro una mano, al darme vuelta, me di cuenta de que era Eugenia y sin más me le eché a llorar, me besó la cabeza y me abrazó fuertemente» (Ulloa, 2011:177).

En casa de los padre de Eugenia, Bernal logra presenciar un exorcismo, luego se da cuenta que la joven, supuestamente posesa, en realidad, está bajo el efecto del psilosybe, a Bernal le parece risible todo el rito, sin embargo, es importante rescatar que aunque trate de ridiculizar la escena, la droga y el demonio también se relacionan, pues como explica Chevalier el demonio posee «una iluminación superior a las normas habituales, que permiten ver más lejos y con más seguridad. Autoriza incluso a violar las reglas de la razón, en nombre de la luz trascendente» (Chevalier, 1986: 407). María Belén cuando consume los hongos, justamente, busca este efecto.

Eugenia se convierte en esa suerte de pitonisa en la vida de Bernal, es un personaje que se relaciona con lo demoníaco o la inversión del orden divino, pues puede predecir, por medio del Tarot, aquello que para los creyentes debe permanecer cifrado, pues solo Dios debería conocer los destinos de cada ser humano.

\section{Lorenzo}

El padre de Bernal es un hombre que se describe como fanático del fútbol, se retrata como alguien que ha fracasado en su propósitos, pues se divorcia por causa de otra mujer, sin embargo, esta lo abandona y lo estafa, se muestra que tiene problemas financieros y su relación con Bernal, tampoco es muy buena, no es un padre abnegado, por el contrario, olvida cuidar a su hijo cuando su exesposa se lo pide, situación 
que Bernal aprovecha para hacer una fiesta: «Mi mama acompañó a Agustín a una gira de bienes raíces a Guanacaste y supuestamente mi papá sería quien estaría al tanto de la casa y de mí(...). Como sabía que mi tata no se aparecería (porque tenía una memoria de teflón), armé la fiesta» (Ulloa, 2011: 23).

En este caso, este padre está muy lejos de la figura del patriarca: cabeza de la familia y de la Iglesia, hay un rasgo físico del padre de Bernal que no deja de ser llamativo, pues, según la mitología cristiana, los árabes son fruto, ya no solo del pecado original del cual desciende la humanidad, sino que se originan del adulterio «porque cuando joven tenía cierto aire arabesco cuyos atributos étnicos habían enloquecido a mi mamá» (Ulloa, 2011:22). En la Biblia Dios profetizó que Ismael y gran parte de su descendencia árabe serian de un carácter «fiero» salvaje (o belicoso) y que «su mano será contra todos, y la mano de todos contra él» (Gen.16:12).

Además este personaje se relaciona con las armas, otra de las herencias que los ángeles caídos entregan a los seres humanos y cuya relación también justifica su apariencia árabe, de acuerdo con el Antiguo Testamento: «Me acordé del revólver que había comprado, de inmediato a la mente me vinieron muchas escenas. Mi mamá reclamándole a mi papá y mi tata muy loco y cansado sacando el revólver para pegarle tres tiros» (Ulloa, 2011:133).

Cuando doña Fabiola comienza a salir con Agustín y a arreglarse para él, Lorenzo le comenta a Bernal que mientras estuvo casada con él nunca lo hizo, Agustín es quien mueve estas actitudes en Fabiola, como propicia el consumo de drogas en su hija, también, es por protegerse de él que Lorenzo compra un arma. Lorenzo es un personaje que quiere desenmascarar a Agustín (el demonio), pero no lo logra, excepto, por una pesadilla de Bernal, donde él encarnado en su padre mata a Agustín.

\section{Fabiola}

En Vidas de Santos de Butler (1965:627) se narra que Santa Fabiola, tras enviudar de su segundo esposo, hizo penitencia en Belén. El referente resulta curioso, pues Fabiola (la madre de Bernal) también se casa dos veces y es Belén, quien le ocasionará, indirectamente, el mayor dolor de su vida: la muerte de su hijo.

La madre de Bernal se describe como una mujer obsesionada con su trabajo, pero alguien que además se preocupa por su hijo. Una mujer autosuficiente y exitosa, ¿qué relación podría tener ella con el mal? A simple vista, ninguna. No obstante, como parte de este universo creado por el autor en donde todos los personajes parecen hacer efectiva una de las enseñanzas de los ángeles caídos, aquellos que, según el mito, prefirieron el pecado a la perfección del cielo, este personaje se relaciona, efectivamente, con el maquillaje, otra de las herencias que, según se relata, los ángeles caídos dejaron a los seres humanos.

Bernal comenta: «Mi mamá se puso implantes, por recomendación, aunque no lo aceptó, de Agustín. Sería el regalo de noche de bodas que ella le daría (...) y fueron la clausura de un proceso de embellecimiento que había empezado con los spa, los pilates, el spinning, sesiones de bronceado y evolucionó hasta la depilación con láser y las inyecciones de bótox» (Ulloa, 2011:182).

La madre de Bernal, cuando inicia su relación con Agustín, empieza a obsesionarse con la belleza, vuelve a cuidar su figura y utiliza la tecnología disponible para mantenerse hermosa, esta conducta, de acuerdo con la mitología cristiana, la introducen los ángeles caídos, quienes enseñan a los hombres y mujeres a embellecerse, a alterar su apariencia para lucir mejor.

\section{Ofelia}

El nombre Ofelia viene del término griego "ofeles" que significa ayuda. Este nombre, inmortalizado en Hamlet, parece ser un elemento en común de la novela Bajo la lluvia Dios no existe con la obra de Shakeaspeare, Ofelia la joven novia de Hamlet pierde la razón. La madre de Mabe se describe como una mujer que intenta refugiarse en ideologías new age 
para no sucumbir al dolor. Su vida al lado de Agustín fue degradante, él la obligaba a tener relaciones sexuales con muchachos y la filmaba, ella soportó esto, pero cuando se enteró que él abusó de su hija mayor y trato de abusar de Mabe, no pudo más. Luchó por la custodia de sus hijas, pero no logró nada y aunque, su nombre significa la que ayuda, ella no logra salvar a su hija, ella se preocupa por María Belén, pues sabe que tiende a deprimirse y habla con Bernal para que le cuente cómo está su hija, pero ella no logra salvarla ni de Agustín, ni del suicidio. La madre de Mabe es un personaje que vive en un aparente y total equilibrio: sin embargo, siempre está inquieta por el daño que su exmarido pueda causarle a sus hijas. En ella hay una inversión del discurso, no es la madre que cuida a sus hijas, ella es la madre que acaso puede mantener su propia calma, en el entierro de su hija menor, Mariel, su hija mayor es quien trata de calmarla, es la madre inversa, la inversión es también una característica de lo maligno, como lo explican Ovares y Rojas en El sello del ángel, refiriéndose a la alteración del universo narrado en la novela El señor presidente: "es un mundo invertido, en el que Dios ha sido sustituido por el demonio, la omnipresencia y el poder total del tirano. En la tragedia de la ignorancia o la inocencia, la gente pierde entonces el sentido cabal de las cosas o interpreta al revés la identidad de sus semejantes" (Ovares y Rojas, 2000:174).

Este personaje representa la inversión del poder en el mundo narrado, "la que ayuda" no puede ayudar, la del orden aparente es la menos equilibrada emocionalmente, la madre es custodiada por las hijas. Doña Ofelia se reúne con Bernal y le dice "Mirá Bernal, te llamé porque vos sos el novio de mi hija y creo que vos a estas alturas la conocés mejor que yo» (Ulloa, 2011:131). Mabe entra en la vida de Bernal en el mes de mayo, muere o se suicida, mejor dicho, a finales de noviembre, tras nueve meses de que Bernal conoce a su hija, doña Ofelia parece cederle a Bernal la responsabilidad sobre Mabe y afirma que él la debe conocer mejor que ella, en un orden "tradicional" se dice que nadie conoce a los hijos como la madre, pero en un mundo al revés, los padres son tan desconocedores de sus hijos que solicitan que los niños se cuiden entre ellos, los adultos son tan infantiles e irresponsables que los hijos, en este caso Mabe, se niega a la maternidad. Se niega a tener un hijo para que viva en un mundo donde reina el caos, un mundo al revés, un mundo de mierda, que recuerda más al infierno, que a la Tierra.

\section{Agustín}

Es quien ordena este mundo, en torno a él se teje toda la maldad y la degradación si existe el diablo en esta novela está encarnado en este personaje. Una vez que la vida de los personajes se cruza con la suya, todo empieza a descomponerse, sin embargo él se mantiene incólume. La primera advertencia sobre el tipo de personaje que es Agustín se la hace Mabe a Bernal: «iMae, dígale a su mamá que rompa cualquier relación con Agustín, no sabe con quién se está metiendo, me advirtió» (Ulloa, 2011:58). Más tarde es Lorenzo (padre de Bernal) quien le advierte que Agustín no es una buena persona: «Es un cabrón (...) siempre ha estado relacionado con gente de poder. Ministros, diputados y candidatos presidenciales» (Ulloa, 2011:85).

Ofelia es la primer víctima, le sigue su hija Mariel, así cientos de jóvenes a quienes utiliza para prostituirlas. Ratatás es víctima y cómplice de los manejos oscuros de Agustín, asimismo Valeria, Fabiola y hasta Lorenzo se ven perjudicados cuando este personaje se cruza por sus vidas, pues desencadena la pérdida que ellos como padres también sufrirán, tras el suicidio de Bernal. Mabe le anuncia a Bernal: «Me preguntó en cuántas vidas se habrá cagado Agustín» (Ulloa, 2011:107). Esto incluye la vida de la madre de Bernal, pues ella le advierte: «tu mamá, aunque no lo creás, cayó en la misma telaraña en donde estamos mi mamá y yo, y por más buena abogada que sea no podría salir de ese hueco. Creáme, yo sé por qué se lo digo. Agustín es un hoyo negro, todo lo que toca lo consume y lo echa a perder, pero si quiere vaya y le dice a su mamá quién es Agustín, pero no 
le va a escuchar ni aunque mi mamá y yo le vayamos a contar» (Ulloa, 2011:107).

Es Agustín quien provoca que Mabe se deprima, pero es también él quien le enseña el gusto por el arte, la palabra que debería dar vida, que en el relato bíblico se usa para crear en este caso el amor por la escritura se utiliza para dar forma a un mundo oscuro y tormentoso en el que es la muerte quien triunfa, como lo señalan Ovares y Rojas cuando el mundo narrado se encuentra al revés «la palabra se revela en su dimensión negativa: en vez de comunicar, sirve para manipular, mentir y matar» (Ovares y Rojas, 2000: 175). Tras discutir con Agustín Mabe le confiesa a Bernal: «Estaba tan llena de odio que era capaz de hacer una locura. Solo Agustín es capaz de provocarme esos sentimientos» (Ulloa, 2011:104).

La palabra heredada por el demonio no cumple con el papel de crear o comunicar, sirve para confundir a Mabe, quien ve en el final de su poemario el final de su propia vida y en la muerte la única salida para evitar un nacimiento y la repetición de otra historia, de otra vida tormentosa y sufriente como la suya.

\section{Bernal}

Este personaje es el punto donde se cruzan todos los destinos, funciona, en este sentido como un ángel, según explica Chevalier los ángeles son intermediarios entre Dios y el mundo, excepto que Bernal no es intermediario de Dios, pues este no existe, es el mediador entre el mundo de Agustín y los otros personajes, entre Mabe y su madre, entre la clase social de Eugenia o Ratatás y la suya, él transita el mundo de Mabe, el mundo de la drogas, del sexo, el mundo superficial y vacio en que vive y el mundo atormentado, pero seducido por el arte de María Belén.

Bernal nunca entiende la sensibilidad artística de Mabe y la única vez que las palabras de María Belén lo hacen reaccionar es cuando lee la carta que ella le deja, cuando se entera de que ella mató al hijo que hubieran podido tener, Bernal se entristece, pero su reacción es la de seguirla, nuevamente va tras de Mabe en busca de una nueva experiencia que justifique su mundo, pues sin ella su vida vuelve a ser tan plana como antes y deja de tener sentido.

En un sueño Bernal describe el infierno, cuando preso en el cuerpo de su padre mata a Agustín y a su madre, sin embargo, cuando despierta, está consciente de no tener el poder para matar a Agustín, de esta manera decide quitarse la vida y beber el regalo que le dejó Ratatás por su amistad, una infusión de reina de la noche, lo que le asegura, al menos, la muerte cerebral. Desde el inicio de la novela es Bernal quien nos conduce por el mundo narrado, son sus ojos los que nos permiten ver lo que pasa.

\section{Conclusiones}

De acuerdo con Centini (2004:10) el contacto entre los ángeles y los hijos de los hombres da lugar a dos tipos de pecado, el primero relacionado con la unión de las mujeres con los ángeles, que generó a unos gigantes monstruosos; y el segundo que concierne a las enseñanzas atribuidas a los ángeles que bajaron del cielo: encantamiento y magia; corte de plantas y raíces; producción y manipulación de las armas; uso de joyas, adornos y cosméticos; astrología. En cada una de estas áreas se puede ubicar a un personaje de la novela: en la primera a don Timoteo, padre de Eugenia; en la segunda a Ratatás; en la tercera a don Lorenzo, padre de Bernal; en la cuarta a doña Fabiola, madre de Bernal y en la quinta a Eugenia.

Chevalier (1986:414) afirma que el diablo simboliza todas las fuerzas que turban, obscurecen y debilitan la conciencia y determinan su regreso hacia lo indeterminado y lo ambivalente: centro de la noche, por oposición a Dios, centro de luz. El uno arde en un mundo subterráneo, el otro brilla en el cielo. En la novela de Warren Ulloa existe un personaje cuyo poder altera todas las vidas, se reconoce como alguien que produce daño y dolor, la intención del demonio es el poder, poder que Agustín adquiere en la vida de los personajes, por medio de su encanto, sus contactos o su dinero, de esta manera se constituye en un ser demoníaco. 
El personaje de Agustín se codea con el poder político del país, en esta novela se muestra mucho del descreimiento en los procesos políticos o legales en Costa Rica, su poca transparencia y eficacia hacen que Agustín sea intocable.

La novela muestra la realidad de muchos hogares, Bernal es el típico adolescente promedio, desconoce la historia del país, no le interesa involucrarse intelectualmente con nada, la única vez que cita una fuente de conocimiento es Discovery Channel. Su incursión con las drogas la hace por Mabe, pues es un joven sin criterio, lo único que quiere es tener relaciones sexuales con Mabe, pero nunca mide las consecuencias, ni ve más allá de su nariz. Mabe, por el contrario, es una joven que sabe lo que quiere, usa el hongo para experimentar con la escritura y en el estado que ella define como más lúcido concluye que dios no existe, sin embargo, todo parece apuntar que el diablo sí, su propio padre es un ejemplo de ello.

La escritura representa el final, el final del poemario libera a Mabe de su misión en el mundo y la lectura de la carta golpea a Bernal contra la realidad: Mabe se mantuvo viva para concluir su poemario, él solo entiende la vida si está junto a ella, la muerte es quien cierra el círculo, no habrá una nueva víctima para Dios o para el diablo, al menos, no una engendrada por María Belén o Bernal.

\section{Bibliografía}

Butler, Albán. 1965. Vidas de Santos. México: Clute.

Chevalier, Jean. 1986. Diccionario de símbolos. Barcelona: Herder.

Centini, Massimo. 2004. El ángel caído. Barcelona: De Vecchi.

García Font, Juan y García Jorba, Juan M. 1996. Crónicas de Satán. Barcelona: Idea Books.

Eliade, Mircea. 1991. Mito y realidad. Barcelona: Editorial labor.

Ovares, Flora y Rojas Margarita. 2000. El sello del ángel. Heredia: EUNA.

Papini, Giovanni. 1968. El diablo. Buenos Aires: Emecé.

Pérez-Rioja, José Antonio. 1988. Diccionario de símbolos y mitos. Madrid: Tecnos.

Ulloa, Warren. 2011. Bajo la lluvia Dios no existe. San José: Uruk.

Zania. 1994. Diccionario esotérico. Buenos Aires: Kier.

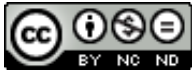

Este obra está bajo una licencia de Creative Commons Reconocimiento-NoComercial-SinObraDerivada 4.0 Internacional. 
